\title{
Teologiske Studenter fra Hertugdømmet Slesvig i Aarene 1814-1864
}

\section{Ved Thomas Otto Achelis}

I de tre og et halvt Aarhundrede fra Reformationen indtil 1864 har Landet mellem Ejder og Kongeaa produceret over 10.000 Studenter. Da der ikke fandtes Universitet i Hertugdømmet, var disse unge Slesvigere nødt til at studere udenfor deres snævre Hjemstavn, og vi møder dem derfor paa snart alle Højskoler, i Bologna og Upsala, i Dorpat, Oxford og Paris, i Tyskland, Danmark, Sverige, Holland, England, Frankrig, Svejts Italien og Estland. Af denne lange Periode er Aartierne fra 1814 til 1864, fra Kielfreden til Fredsslutningen i Wien særlig omskiftelig. I dette Tidsrum vaagner Slesvig til national Bevidsthed - baade til dansk og tysk - og i denne Periode begynder den danske Regering, som fra 1779 var Herre over h e le Hertugdømmet, at drive en bevidst dansk Politik.

Af de unge Slesvigere, som i Aaret 1814 begyndte deres Studier, var de fleste Teologer, og det samme var Tilfældet $i$ 1864, da Østrigerne og Preusserne erobrełe Landet og skabte aldeles forandrede Forhold. Af de 395 Slesvigere, som i Aarene 1814-1823 blev indskrevne ved Universiteterne, var de 158 Teologer, det er mere end $42 \%$, medens $40 \%$ studerede Ju:a og $13 \%$ Medicin. I Slutningen af Perioden, i de ti Aar fra 18551864, blev kun 267 Slesvigere Studenter; det er 128 eller næsten $30 \%$ mindre. Af disse var $30,9 \%$ Teologer, $27,7 \%$ Jurister, $18,7 \%$ Medicinere og $22,1 \%$ studerede ved det filosofiske 
Fakultet. Dette betyder en Aftagen hos Teologerne og Juristerne, en Tiltagen hos Medicinere og Filosofer. Alligevel var indtil 1864 Teologerne relativ stærkest repræsenterede i den akademiske Ungdom i Hertugdømmet.

Ialt har der været 615 teologiske Studenter i dette halve Aarhundrede. Jeg ser bort fra dem, som begyndte med Teologien, men gik over til et andet Studium eller blev Lærere. Af de 158 unge Mænd, som i Aarene 1814-1823 begyndte det teologiske Studium, var næsten en Trediedel Bøndersønner, 28,1\%. ${ }^{1}$ ) Først efter Udskiftningen, Ophævelsen af Livegenskabet og den deraf følgende økonomiske Udvikling blev det muligt for en Gaardmand at betale en eller flere Sønners Studium. Sønner af Inderster eller Kaadnere forekom kun meget sjældent som Studenter. I de sidste ti Aar, fra 1850-1864, var omtrent lige saa mange teologiske Studenter af Bondeslægt. Derimod voksede Antallet af Præstesønner blandt de teologiske Studenter, medens 1814-1823 godt og vel hver femte var Præstesøn, var 1855-1864 mere end hver tredje det. Det er paafaldende, at Tallet paa Degne-, Organist- og Lærersønner, som blev teologiske Studenter, aftog betydeligt. 1814-1823 udgjorde de næsten 10 pct., 1855-1864 kun 4 pct. Omvendt var der i de første ti Aar, kun 3,4 pct., som var Sønner af ikke-teologiske Akademikere, Læger eller Lærere ved højere Skoler, men i de sidste ti Aar er der dobbelt saa mange af dem, 8,7 pct. Kun forholdsvis faa Købmænd eller Haandværkere lod deres Sønner studere Teologi. Det er paafaldende, at saa faa fra Byerne valgte det teologiske Studium, hvilket vistnok hænger sammen med Borgerstandens materialistiske Indstilling. Mens Eondekonen drømte om at se sin Søn paa Prædikestolen i Sognekirken, tænkte Købmanden og Haandværkeren paa, hvorledes Sønnen kunde tjene de fleste Penge. Han kendte Advokater og Læger i Købstaden, som var mere velstaaende end Præsterne paa Landet. Kun en eneste Gang, i 1845, paabegynder en Arbejdersøn det teologiske Studium. Fra Landet, baade 
fra Præstegaarde og Bondegaarde, kom næsten Halvdelen af de teologiske Studenter i disse 50 Aar. Blandt Præstesønnerne var der mange, hvis Forfædre i Aarhundreder havde været slesvigske Præster. Johann Sigismund Boysen fra GammelHaderslev Præstegaard, som blev Student i 1815, nedstammede fra "Ehr Johan Smidt tho Oseeby in Hadersleue herde", som nævnes i den Haderslevske Kirkeordinans fra 1528. Christian August Valetiner - Student i Kiel 1817 og i Jena 1819 - var en Ætling af den i Flensborg 1642 fødte Wilhelm Valentiner, som senere blev Præst i Munkbrarup. Peter Heinrich Claudius fra Sønderborg - Student i Kiel 1849 og Sognepræst i Tolk fra 1864 - havde som Tipoldefader Emmerlevpræsten Claus Paulsen, som var født i Ribe omkring 1571. Men det er nu Undtagelser, Præstedynastiernes Tid er forbi, i hvert Fald omkring Aarhundredets Midte, og mange Sønner af gamle Præstefamilier maatte herefter forlade Hjemstavnen.

Hvor studerede disse unge? I første Række i Kiel eller i København. ') I 1768 forordnedes det, at alle, der vilde søge et Embede i Hertugdømmerne, skulde have studeret to Aar i Kiel. Efter Ordlyden gjaldt „Bienniet" for alle Slesvigere, i Praksis dog kun for Slesvig Stift, ikke for de til de kongerigske Stifter hørende Omraader. Fra Tørninglen kom Børnene til Ribe Katedralskole, fra Erø og Als - med Undtagelse af Sønderborg og Kegnæs - til Odense, og disse Studenter fra Ribe og Odense mødtes paa Københavns Universitet. Derimod besøgte Eleverne fra det øvrige Slesvig, ogsaa de nordligste Egne, Landsdelens fire lærde Skoler. Fra Sognene syd for Kolding gik Vejen ikke til det nærliggende Kolding, men til Haderslev, og dette betyder i Reglen tillige: ikke fra Kolding til København, men fra Haderslev til Kiel. Her gør de Grænser sig gældende, der kan spores tilbage til Kristendommens Indførelse og som først blev udvisket, da Nationalitetsbevidstheden vaagnede. Vigtigere end Kongeaaen, som skiller Jyder fra Jyder, var Stiftsgrænserne, som betød meget, inden Nationalitetskampen søn- 
derrev dem. Indtil Midten af det 19. Aarhundrede var Antallet af slesvigske Teologer, som kom til Københavns Universitet, mindre end Antallet paa dem, som drog til Kiel, idet kun 13 pct. af Hertugdømmernes Indbyggere levede $\mathrm{i}$ de kongerigske Stifter. Fra 1814 til 1864 læste 329 teologiske Studenter udelukkende i Kiel, 110 kun i København, deraf 1850 til 1864 udelukkende i Kiel 21 og i København 38.

Undtagelser fra Reglen: Studenter fra Slesvig Stift gaar til Kiel, Studenter fra de kongerigske Bispedømmer til København, findes undertiden. Men indtil 1830 gaar nøjagtigt det samme Antal fra Tørninglen, Als og Ærø til Kiel som fra Slesvig Stift til København. Efter 1830 vokser Antallet af Studenter fra Slesvig Bispedømme i København lidt.

I 8 Aartier bestod „Biennium“. Ophævelsen for Slesvigs Vedkommende hilstes med Indignation fra slesvig-holstenske Kredse. Dertil kom Omdannelsen af de lærde Skoler, Husum Latinskole blev nedlagt, Skolen i Haderslev blev dansk, Flensborg Latinskole fik blandet dansk og tysk Undervisningssprog, og kun Katedralskolen i Slesvig beholdt tysk. Samtidig blev Skoleaaret forandret, svarende til Københavns Universitets Ordinarium. For Forældre, som ønskede, at deres Sønner fik en Stilling i Hjemstavnen, blev det en Fordel at lade dem studere i Kobenhavn.

Efter 1848 aftager Studenternes Tal stærkt. Medens der fra 1815 til 1848 gennemsnitlig var 15 unge Mennesker om Aaret, som begyndte et teologisk Studium, var det fra 1849 til 1864 kun 5. Tiderne mellem Krigene var Opgangstider, og Lysten til akademisk Studium er derfor sunket stærkt. Paa àen anden Side er det interessant at lægge Mærke til, at Antallet af sønderjydske Teologer ved Københavns Universitet tiltcg fra 1849. I Aarene fra 1849 til 1864 læste 43 teologiske Studenter fra Slesvig i København, 23 i Kiel, 25 paa begge Universiteter, 43 i Kiel og paa andre tyske Universiteter. Man mærker Forskellen, naar man sammenligner med Tiden før 1849. 
I Aarene 1833 til 1848 studerede 69 Teologi udelukkende i Kiel, udelukkende i København 25, ved begge Universiteter 2, i Kiel og ved tyske Universiteter 62. Man mærker en Tiltagen af Tallet paa teologiske Studenter fra Slesvig i København, hvilket fremgaar af nedenstaaende Opstilling.

\begin{tabular}{ccccc}
\hline & Kun Kbhvn. $\begin{array}{c}\text { Kobenhavn } \\
\text { og andre } \\
\text { Universiteter }\end{array}$ & $\begin{array}{c}\text { Kun } \\
\text { Kiel }\end{array}$ & $\begin{array}{c}\text { Kiel og andre } \\
\text { Universiteter }\end{array}$ \\
$1849-52$ & 3 & 9 & 5 & 19 \\
$1853-56$ & 10 & 16 & 2 & 16 \\
$1857-60$ & 13 & 17 & 3 & 21 \\
$1861-64$ & 13 & 19 & 13 & 29 \\
\hline
\end{tabular}

Det er Tal, men bag Tallene staar Overvejelser og Afgørelser, Haab og Bekymringer. Det har noget at betyde, naar slesvigske Forældre sendte deres Sønner, som det tit skete i disse Aar, til Latinskoler i Holsten. De maatte derefter regne med, at Sønnerne ikke let kunde faa Ansættelse mellem Kongeaa og Ejder.

Det er ogsaa sket, at slesvigske Studenter opgav Studiet i København og rejste til Kiel. I 1861 rettede 42 slesvigske Studenter i København, til hvem der senere sluttede sig andre 20, patriotiske Adresser til Krigsministeren og stillede sig til Raadighed $\mathrm{i}$ en truende Krig mod Tyskland. I disse Adresser var de Kielske Studenter fra Tiden før 48 betegnet som „underviste i Løgn og oplærte til Meened. ${ }^{3}$ ) De, som ikke vilde eller kunde underskrive Adresserne, kom til Kiel, hvor de forresten ikke blev vel modtaget. Og den samme Vej gik 6 teologiske Studenter i 1864, alle efter Slaget ved Dybbøl.

Mens de slesvigske Studenter i København i Reglen kun har besøgt dette Universitet, indskrænkede deres Studiefæller, som var gaaet sydpaa, sig ofte ikke blot til at gaa til Kiel. 4 Semestre var de nodt til at blive der. Af 665 unge Teologer kom 329 , d. v. s. omtrent Halvdelen, kun til Kiel, men 110 eller næ- 
sten hver sjette til København, Resten, d. v. s. næsten hver tredje har ogsaa besøgt andre Universiteter. Hvad gav Anledning dertil? J. S. M. Ostenfeld mener, at det var ret dyrt at leve i Kiel, og at dette maaske har "været medvirkende til, at mange af Landets egne Studenter nøjedes med at opholde sig det lovbefalede Biennium i Kiel og saa fuldende deres Uddannelse ved andre Universiteter. "“) Hvis dette er rigtigt, saa har de nævnte 329 teologiske Studenter været meget ukloge. Det er netop de fattige Studienter, som tilbragte alle 3 Aar ved Christian-Albertina i Kiel. En tysksindet Slesviger, som var Student i København mellem Krigene, fortæller noget andet. „Kiel har altid kun haft enkelte videnskabelige Kapaciteter, men ogsaa kun enkelte. Den som længtes efter en dybere gaaende Almendannelse og hvis kulturelle Krav ikke blev tilfredsstillet gennem de der serverede hjemmebagte Brød, (,die dort aufgetragene hausbackne Kost"), søgte altid, hvis det var muligt for ham, mindst et Aar, Ophold paa et større Universitet i Tyskland. ${ }^{\text {"5) }}$ Den sande Aarsag er vistnok den Overvejelse, at det er mere dannende for et ung Menneske at besøge flere Universiteter.

Hvilke Universiteter har de unge Slesvigere saa opsøgt foruden Kiel og København? Naturligvis kunde kun saadanne Universiteter komme i Betragtning, som havde et lutherskteologisk Fakultet. Derfor gik kun Ikke-Teologer til München eller Würzburg. Ni Universiteter er i det halve Aarhundrede fra 1814 til 1864 besøgt af teologiske Studenter fra Hertugdømmet, de 3 preussiske i Berlin, Bonn og Halle, det hannoveranske Göttingen, Jena og Leipzig i Mellemtyskland, Erlangen, Heidelberg og Tübingen i Sydtyskland. De fleste gik til Berlin (66), saa følger Erlangen (34), Bonn (30), Jena (23) og Halle (20), de øvrige fire er kun opsøgt af enkelte (3-13). Af de 66, som gik til det nygrundlagte Universitet i Berlin, kom Halvdelen i Aarene 1814 til 1827; efter 1848 kom kun 8 til Preussens Hovedstad. I Halle var der indtil 183016 Slesvigere, derefter kun 4, efter de berygtede Halleske Denuntiationer ophørte Besøget 
næsten fuldstændigt. Til Jena er der efter 1838 kun kommet 2 Teologer. Fra 1836 gik Strømmen til de to Universiteter Bonn og Erlangen, til Bonn særlig før 1848, til Erlangen især efter 1850. I Aarene 1850 til 1864 har der i Erlangen været næsten lige saa mange unge Teologer fra Hertugdømmet som samtidig i Berlin, Bonn, Göttingen, Halle, Heidelberg, Jena og Tübingen tilsammen.

Kiels Universitet, kaldet Christian-Albertina efter den gottorpske Hertug, som havde grundlagt det, var fra 1773 ifølge Mageskiftetraktaten med Rusland det andet Universitet i den dansk-norske Helstat. Universitetet laa imidlertid paa tysk Jord og havde tyske Professorer, og denne dobbelte Forbindelse mod Nord og mod Syd bliver udtrykt i det akademiske Konsistoriums S'krıve.ser, som begynder saaledes: "Vi Prorektor, Dekaner og samtlige Professorer ved det kongelige danske, hertugelig slesvig-holstenske Christian Albrechts-Universitet i Kiel,"i) Antallet af udenlandske Studenter aftog, da Indfødsretten kun gav Danskere, Nordmænd og „Holstenere“ Adgang til Embeder. Sommeren 1814 var 13 pct. af Studenterne i Kiel født udenfor Hertugdømmerne, i det følgende Vintersemester kun 9 pct. Efter Norges Tab omfattede Helstaten kun Danmark og Hertugdømmerne. ${ }^{8}$ )

Medens Studenterne ved de tyske Universiteter deltog i Kampen mod Napoleon, den "vesle Korsikaneren“, som Nordmændene siger, har ingen fra Kiel, en eneste fra Hertugdømmet Slesvig været med. En Student i Heidelberg skrev 1813 til sine Forældre i Augustenborg: "Gerne var jeg gaaet med, da alle mine Venner i Skarer ilede bort, og det voldte mig tit megen Besvær, ikke at blive revet med af den almindelige Enthusiasme" ${ }^{(8)}$, men tiltrods for sin Begejstring for Tysklands Kamp foretrak han - at gaa til Göttingen. Ved Sehested kæmpede de danske Tropper sejrrigt imod en femdobbelt Overmagt. Nogle Maaneder senere opfordrede Karl Theodor Welcker, som lige var kommet til Kiel som Professor i Lovkyndighed, Studenter- 
ne til at fejre Aarsdagen for det store Slag ved Leipzig og var meget forbavset over, at Studenterne foretrak at feste for Sehested. Han kunde ikke lade været at skælde dem ud for deres „Danismus“. $\left.{ }^{10}\right)$ Det kan være tvivlsomt, hvorvidt Welcker, som lige var kommet til Kiel, i det hele taget var i Stand til at bedømme Studenternes nationale Indstilling. Han savnede hos dem de tyske Følelser, som var tilstede ved de andre Universiteter, hvor Studenterne havde været med i Krigen. Men at Studenterne i Kiel i Almindelighed ikke var dansksindede, ser man af den Begejstring, hvormed Indbydelsen til Festen paa Wartburg blev modtaget (August 1817). „Lev vel, indtil vi kan hilse paa hverandre som Bradre og som Tyskere kan fejre vor store Landsmands Minde, som altid for os vil staa som det reneste Eksempel paa tysk Nationaldyd" ${ }^{\prime 1}$ ). At disse Ynglinge skriver om Luther, men tier om Slaget ved Leipzig (Folkeslaget), er forstaaeligt, men betegne Luther som "vor store Landsmand"kunde ingen dansk Student gøre. Omtrent 30 Studenter fra Hertugdømmerne deltog i Festen, det er næsten 16 pct. af de Studerende, fra det store Universitet i Berlin var der ligeledes kommet 30, fra Heidelberg næsten 8 pct., fra det nærliggende Leipzig mindre end 5 pct. De $500 \mathrm{~km}$ havde disse Studenter fra Hertugdømmerne tilbagelagt til Fods, mens de mageligere ni Mecklenborgere foretog Rejsen til Vogns. Denne Rejse betyder en Bekendelse baade til Protestantismen og til Tyskland. Men denne Bekendelse sker indenfor Helstatens Rammer; ingen tænkte dengang paa en Adskillelse fra Kongeriget. At der kom nye aandelige Strømninger til Kiel, skyldes dels nogle unge Professorer, dels den Paavirkning, som Studenterne fik ved Besøg fra andre Universiteter. Af de Slesvigere, som blev Studenter i Aarene 1815 til 1818, har over Halvdelen været paa andre tyske Højskoler. Der blev de vakt i tysk Aand og fik saa i Kiel Indflydelse paa de Studenter, som ikke havde studeret andetsteds.

Af de 111 slesvigske teologiske Studenter, som begyndte deres Studier i Aarene 1814 til 1823, har mere end en Trediedel 
haft Lejlighed at lære tyske Studenters Følelser og Tanker i Tiden efter Frihedskampene at kende. Derfor kunde Studenterne i Kiel Sommeren 1818 skrive: „Ingen af de tyske Stammer skal herefter staa uden for [det tyske Fællesskab] og ubekymret om andre kun tænke paa deres eget Vel. I et tysk Fædreland skal alle finde sammen, og det fælles Fædrelands Lykke og Sorg skal bestemme de enkelte Stammers Lykke og Sorg “"11) Til disse "tyske Stammer" hørte uden Tvivl Holsten, maaske efter manges Opfattelse ogsaa Slesvig. Den tidligere nævnte Student Christian August Valentiner fra Flensborg kom 1820 fra Jena tilbage til Kiel og var meget utilfreds med den Aand, han fandt her: „Da jeg var vendt tilbage til Kiel, deltog jeg $\mathrm{i}$ at splitte og oplese det her endnu i den gamle Aand eksisterende Studenterforbund, hvis Motto var: aldeles ingen politisk Begejstring og Uddannelse eller, hvis det absolut var nodvendigt: for „Schleswig-Holstein“" “12) I December 1821 kom det til et Opgør mellem den gamle "landsmannschaftliche“ Retning og den „burschenschaftliche". Valentiner var med til at stifte Studenterforeningen "Germania“, et „Burschenschaft" efter Jenas Forbillede, som af sine Medlemmer ved Optagelsen krævede en Bekendelse til det tyske Folk. Da Valentiner 1833 sad i det akademiske Fængsel, "Carcer" kaldet, skrev han i Protokollen omtrent følgende: „Ogsaa mig har man bragt 8 Dage til dette Fortabelsens Sted og lod mig underskrive „consilium abeundi“"13). Her har vi siddet som Ledere af en Studenterforening, som kaldte sig Germania. Vi har syndet imod en forældet Tidsalders forældede Bogstav. Vi har deltaget i Fredens Tid i en Del af den Kamp, som man kan kalde Krigen efter Krigen. Fædrelandet, som vi fandt i vort Folk, var den Tanke, til hvilken vi næst efter Troen knyttede vort Liv" $\left.{ }^{\prime 14}\right)$. Denne teologiske Student fra Flensborg maa nok betegnes som tysksindet. Det samme gælder for alle, som sluttede sig til den „burschenschaftliche“ Forening. Disse unge Mennnesker drømte om et forenet Tyskland, om en tysk Nationalstat. - Lidt anderledes var det for 
Korpset (Holsatia), hvis Medlemmer af principielle Grunde var politisk indifferente. Ogsaa deriblandt fandtes teologiske Stucienter, indtil 1836 et Samfund af Teologistuderende, det ældste ved et tysk Universitet, blev stiftet. Aaret 1848 tvang alle til at tage et nationalt Standpunkt, men Afgørelsen var meget vansikelig for mange. Lettest var det uden Tvivl for dem, som kom fra de kongerigske Stifter. Men i Slesvig Stifts nordlige Del stod Modersmaalet paa den ene Side, den tyske Undervisning i Latinskolen paa den anden. 25 teologiske Studenter fra Hertugdømmet forblev i Krigsaarene paa Universiteterne, de 5 i København, de 20 ved tyske Universiteter udenfor Kiel. ${ }^{15}$ ) De sjælelige Kampe, som en ung Haderslev Student fra et tysk Hjem var udsat for, giver nogle Linier af et Brev til Forældrene et Indblik i: „Jeg har altid sagt: Mit Sprog er tysk, mine Digtere skrev tysk, hele mit Væsen er tysk og netop derved stik modsat de herværende Studenter; Moder, Hjemstavn, Fader er for mig tyske og meget andet - kun den Smule Dannelse, som jeg ejer, er tildels af dansk Oprindelse $\left.{ }^{a 16}\right)$. Brevet er skrevet i 1861, da de "patriotiske Adresser" tvang ham til at forlade København. ${ }^{17}$ ).

Tre Aar senere bragte Krigen store Forandringer. De fire lærde Skoler fik atter tysk Undervisningssprog, men beholdt foreløbig dansk som Undervisningsfag..$^{8}$ ) „Biennium“ blev snart ophævet, og de teologiske Studenter blev fritstillede m. H. t. Valg af Universitet, naar de blot i tre Semestre opholdt sig ved et af de preussiske Universiteter ${ }^{17}$ )., til hvilke nu ogsaa Kiel (fra 1867) hørte. 


\section{Anmærkninger}

1) Se Bilag 1.

2) Se Bilag 2.

3) Danevirke 18/2 1861, jfr. Archiv für Kulturgeschichte, Bd.17 (1928), S. $303-304$.

4) J. S. M. Ostenfeld: Stemninger og Tilstande i Holsten (1909), S. 129. Ved Retten i Augustenborg forklarede Væveren Christian Hansen 14/10 1828, at hans Søn Frederik Christian (se Arends I, 314) som Student i Kiel aarligt fik 80 r. Cour., ellers hverken Underst $\varnothing$ ttelse eller Stipendium.

5) Das Studentenwesen und die Studentenverbindungen auf der Universität Kiel. Ein Beitrag zum Verständnisz der schleswig-holsteinischen Bewegungspartei. Von einem Schleswiger: Berliner Revue, Social-politische Wochenschrift, Bd. 42, 3. Quartal/1865/, S. 166. Kiel hat immer nur einzelne tüchtige wissenschaftliche Köpfe gehabt, aber auch nur Einzelne. Wer daher nach einer tieferen allgemeinen Ausbildung trachtete und dessen Culturansprüchen die dort aufgetragene hausbackne Kost nicht genügte, der suchte womöglich stets, wenigstens auf eine Jahr, den Aufenthalt auf einer grösseren deutschen Universität Deutschlands(!) zu ermöglichen *.

B) Se Bilag 3 .

7) Wir Prorector, Dechanten und sämtliche Professoren der Königlich Dänischen, Herzoglich Schleswig-Holsteinischen Christian Albrechts-Universität zu Kiel«. En meget mærkelig Undtagelse findes i *Plan zu einem mit Königlicher Allerhöchster Genehmigung einzuführenden Ehrengerichte für die sämtlichten auf der Königlichen Christian Albrechts Universität zu Kiel Studirenden « (1793, trykt i Provinzialberichte 1793 II, S. 97): *Wir Prorector, Dechanten und sämtliche Professoren der Königlichen schleswig-holsteinischen Universität zu Kiel.\&

8) Litteratur angaaende Studenterne i Kiel 1815-1848 er samlet af R. Bülck i, Kieler Studenten im Vormärz (1940), S. 405-414.

9) Neue Heidelberger Jahrbücher 1936, S. 43: 'Gerne wäre ich mitgegangen als alle meine Freunde hier scharenweise fortströmten, und es kostete mich oft nicht geringe Mühe, mich nicht von dem so allgemeinen Enthusiasmus ergreifen zu lassen.

10) Ostenfeld, 1. c., S. 239.

11) Udgivet ved Otto Scheel i »Kieler Studenten im Vormärz\& (1940), S. 199: «Keiner der deutschen Stämme soll abgerissen für sich bestehen und unbekümmert um andere, nur seinem eigenen Wohle nachjagen. In einem deutschen Vaterlande sollen alle sich wiederfinden, und das Wohl und Wehe dieses gemeinsamen Vaterlandes soll das Wohl und Wehe der einzelnen Stämme bestimmen.* 
12) Udgivet ved R. Bülck i \$Kieler Studenten im Vormärz (1940), S. 317: -Nach Kiel zurückgekehrt hatte ich Teil an der Zersprengung und Auflösung der hier im alten Geiste noch fortbestehenden Verbindung, deren Sinn war: durchaus keine politische Begeisterung und Ausbildung, oder höchstens die für Schleswig-Holstein..

13) Consilium abeundi var en Straf, det akademiske Konsistorium kunde idømme en Student, som havde overtraadt Universitetets Love. Ved subscriptio consilii abeundi c blev han dømt til at forlade Universitetet for Forseelser, som ellers kun blev straffet med akademisk Fængsel (Carcer). Den s Subscriptio consilii abeundi*, som stud. theol. Carsten Erich Carstens fra Tønder, den senere Provst, (se Arends I, 120), har udstedt den 2. Juli 1835, findes gengivet $\mathrm{i} \times$ Geschichte des Corps Holsatia, Kiel (1938), Bilag 15; hans Indførelse i Carcerbogen, dat. -Lauterbach d. 16. Nov. 35), er gengivet $i$, Kieler Studenten im Vormärz (1940), Tavle efter S. 320.

14) Udgivet ved R. Bülck i , Kieler Studenten im Vormärz (1940), S. 317: Auch mich brachte man auf 8 Tage an den Ort der Verdamnisz, und liess das consilium abeundi mich unterschreiben. Wir sassen hier als Vorsteher einer Verbindung, die sich nannte: Germania. Gesündigt hatten wir gegen einen altgewordenen Buchstaben eines altgewordenen Lebens. Mitgekämpft hatten wir in der Zeit des Friedens einen Theil des Kampfes, den du nennen magst: den Krieg nach dem Kriege. Das Vaterland - wir fanden es in unserm Volke - war der Gedanke, an welchen wir nächst dem des Glaubens unser Leben knüpften. *

15) Geschichte des Corps Holsatia, Kiel (1938), Bilag 30.

16) Archiv für Kulturgeschichte, Bd. 18 (1928), S. 303.

17) Jfr, ovenfor Anmærkning 3.

1k) Harald Skalberg: Undervisningen i Dansk ved Universitetet i Kiel og i Hertugdømmernes lærde Skoler efter 1864 (1932) og Zeitschrift für Schleswig-Holsteinische Geschichte, Bd. 77 (1953), S. 219222.

19) H. Ratjen, Geschichte der Universität zu Kiel (1870), S. 21.

Bilag 1: Fodrene til de teologiske Studenter.

\begin{tabular}{|c|c|c|c|c|c|c|c|c|c|c|}
\hline $1814-23$ & 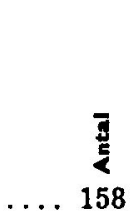 & $\begin{array}{l}\frac{5}{8} \\
\frac{8}{2} \\
35\end{array}$ & 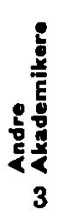 & $\begin{array}{r}8 \\
8 \\
5 \\
5 \\
5 \\
8 \\
8 \\
0 \\
15\end{array}$ & $\begin{array}{c}\mathbf{z} \\
\mathbf{E} \\
\underline{\mathbf{E}} \\
\mathbf{z} \\
\mathbf{x} \\
14\end{array}$ & 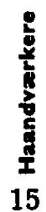 & 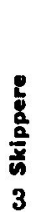 & $\begin{array}{l}\text { to } \\
\text { t. } \\
\text { ch } \\
45\end{array}$ & $\begin{array}{l}\frac{2}{0} \\
\frac{5}{0} \\
3 \\
3 \\
3\end{array}$ & 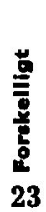 \\
\hline $1824-33$ & $\ldots .215$ & 48 & 12 & 15 & 24 & 31 & 8 & 43 & 8 & 24 \\
\hline $1834-43$ & $\ldots .103$ & 25 & 10 & 15 & 12 & 14 & 1 & 16 & 2 & 8 \\
\hline $1844-53$ & $\ldots$ & 17 & 3 & 6 & 3 & 4 & 1 & 14 & 0 & 3 \\
\hline $1854-64$ & $\ldots \quad 87$ & 29 & 8 & 12 & 4 & 7 & 1 & 24 & 0 & 2 \\
\hline
\end{tabular}


Bilag 2: Besøgte Universiteter.

\begin{tabular}{cccccc}
\hline Aar & & Kiol & Kebenhavn & $\begin{array}{c}\text { Kiel- } \\
\text { Kobenhavn }\end{array}$ & $\begin{array}{c}\text { Kiol og tyoke } \\
\text { Universiteter }\end{array}$ \\
$1814-23$ & $\ldots$ & 101 & 20 & 7 & 39 \\
$1824-33$ & $\ldots$ & 142 & 24 & 4 & 53 \\
$1834-43$ & $\ldots$ & 48 & 20 & 0 & 43 \\
$1844-53$ & $\ldots$ & 18 & 12 & 12 & 31 \\
$1854-64$ & $\ldots$ & 18 & 35 & 15 & 29 \\
\hline
\end{tabular}

Bilag 3: Tyske Universiteter (udenfor Kiel).

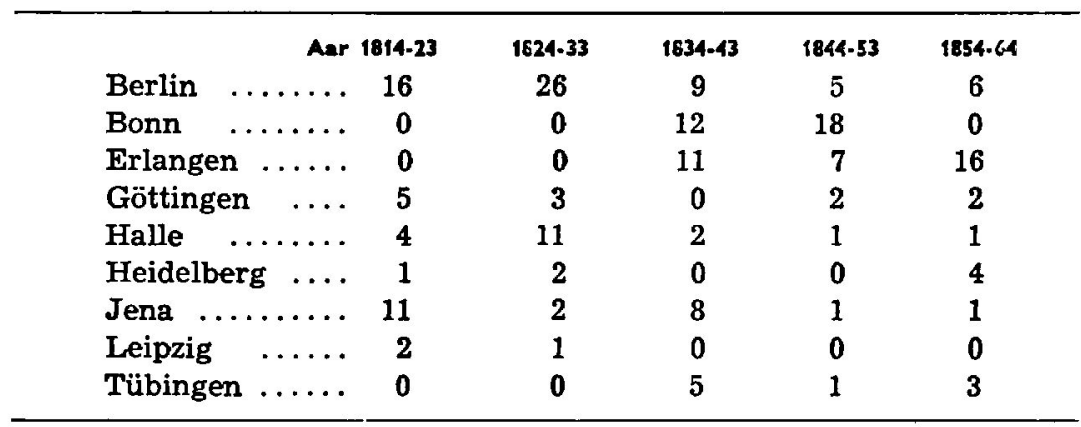

